\title{
PLA DE L'HORTA (SARRIÀ DE TER, GIRONA): UNA NECRÓPOLIS CON INHUMACIONES VISIGODAS EN LA TARRACONENSE ORIENTAL
}

\author{
POR \\ JOAN LLINÀS POL, ANNA TARRÉS FARRÉS, CARME MONTALBÁN MARTÍNEZ, \\ JOSEP FRIGOLA TRIOLA, JORDI MERINO SERRA, BIBIANA AGUSTÍ FARJAS \\ Janus S.L. Girona
}

\section{RESUMEN}

En Sarrià de Ter (Girona) se produjo entre 2004 y 2006 el hallazgo de la primera gran necrópolis visigoda en la Tarraconense oriental, compuesta por 58 enterramientos con ajuares y objectos de ornamentacion tipicamente germánicos (hebillas, apliques, fíbulas...). La existencia de esta necrópolis se debe poner en relación con la proximidad de la ciudad de Gerunda, de la Vía Augusta y del castellum tardoantiguo descubierto recientemente en el muncipio vecino de Sant Julià de Ramis.

\section{SUMMARY}

The first large Visigothic necropolis in eastern Tarraconensis was found in Sarrià de Ter (Girona, Spain) between 2004 and 2006. It is composed of 58 burials with typically Germanic trousseaux and ornamental objects (buckles, fixtures, brooches ...). The existence of this necropolis must be discussed in relation to the proximity of the city of Gerunda, of the Via Augusta and the castellum of Late Antiquity discovered recently in the neighbouring town of Sant Julià de Ramis.

PALABRAS CLAVE: Necrópolis romana. Gerunda. Hebilla. Ajuares visigodos. Siglos II-VI. Via Augusta.

KEY WORDS: Roman necropolis. Gerunda. Buckle. Visigothic trousseaux. 2nd-6th centuries. Via Augusta.

Entre octubre de 2004 y julio de 2006, cuatro campañas de excavación en el barrio del Pla de l'Horta (Sarrià de Ter, Girona), dejaron al descubierto una extensa área de necrópolis que presentaba dos fases claramente diferenciadas: una primera fase romana (siglos II-V) y una segunda fase visigoda (siglo $\left.\mathrm{VI}^{1}\right)^{1}$. Fue el hallazgo de los 58 enterramientos que componían esta segunda etapa del cementerio lo que

${ }^{1}$ Los trabajos fueron sufragados por el Ayuntamento de Sarrià de Ter (2005 y 2006) y los promotores de dos obras particulares que afectaban al yacimiento, Gertrudis Martínez (2004) y Manuel Saavedra (2005). Las cuatro excavaciones, encargadas a la empresa Janus S.L., fueron dirigidas por Josep Frigola y Jordi Merino (2004), Joan Llinàs y Carme Montalbán (2005) y Joan Llinàs y Anna Tarrés (2006). permitió documentar la primera necrópolis con una mayoría de enterramientos visigodos de la Tarraconense oriental, una región donde la presencia de población germánica más allá del ámbito de la administración estatal y del ejército en el siglo vi parece ser que fue poco más que anecdótica.

\section{ENTORNO GEOGRÁFICO Y HISTÓRICO}

Pla de l'Horta está situado a unos $500 \mathrm{~m}$ al oeste del casco antiguo de Sarrià de Ter, que se extiende a lo largo del antiguo trazado del camino real de Barcelona a Francia, hoy convertido en calle. En el extremo sur de la población se encuentra el puente de l'Aigua o Pont Major (Puente Mayor), construido sobre un antiguo puente medieval por donde el mencionado camino real cruzaba el curso del río Ter (Fig. 1). Este puente tenia orígenes y cimientos romanos y cerca de él fue hallado en 1876 un miliario perteneciente a la Vía Augusta 2 .

Durante los años setenta del siglo xx se descubrieron en Pla de l'Horta los restos de una extensa villa romana compuesta por dos cuerpos principales de edificación articulados en torno a sendos patios y por diversas dependencias anejas, algunas de las cuales pavimentadas con excelentes mosaicos ${ }^{3}$. Esta villa se

\footnotetext{
${ }^{2}$ Una buena obra completa sobre la historia de Sarrià de Ter ha sido publicada recientemente (Brugada 2006). En esta publicación hallamos, entre otros datos, una buena síntesis sobre el puente de l'Aigua (pp. 111-116, 133-138, 163-165, 178-179, 344-349 y 361-373) y sobre el miliario de Sarrià (pp. 34-35), además de una primera noticia sobre la necrópolis de Pla de l'Horta (pp. 47-50), la cual tratamos mucho más extensamente en el presente artículo.

${ }^{3}$ No existe una publicación monográfica sobre este importante yacimiento, pero ha sido tratado en varios artículos desde su descubrimiento y excavación. Destacamos los siguientes: Oliva 1970; Nolla 1982-83; Nolla y Sagrera 1993; Palahí y Vivó 1994; Palahí y Vivó 1995.
} 


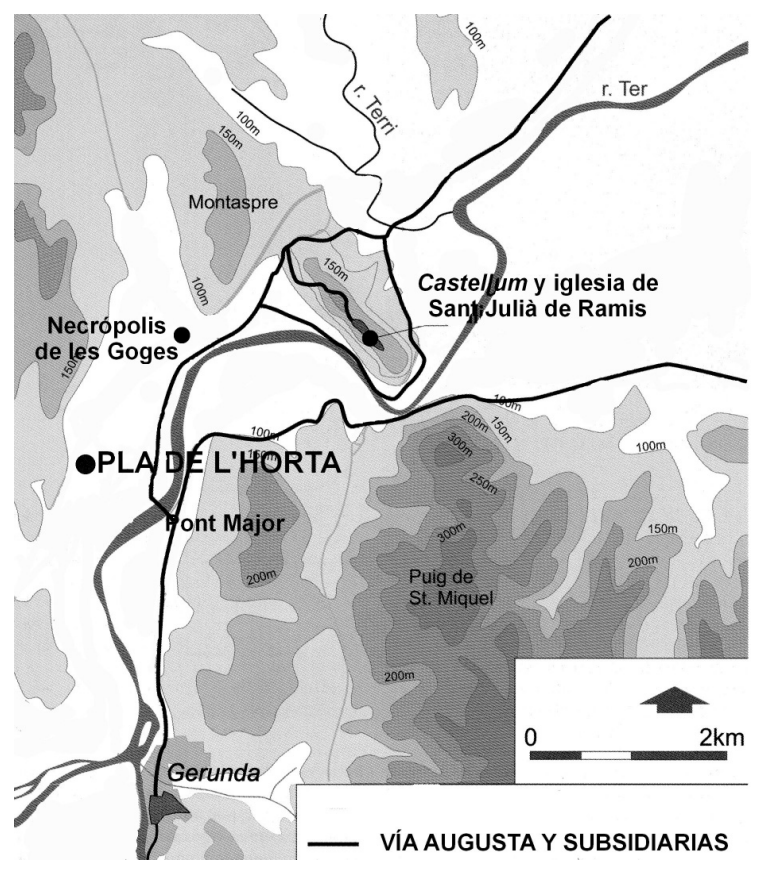

Fig.1. Situación de la necrópolis en relación con la ciudad de Gerunda, la Vía Augusta y los demás yacimientos tardoantiguos de la zona.

ha datado generalmente desde época romanorrepublicana hasta el siglo v d.C., cuando la habría destruído un incendio. Aun así, el hallazgo posterior de algunas inhumaciones en cista ha hecho suponer la existencia de poblamiento en esta zona con posterioridad a esta fecha ${ }^{4}$.

\section{DELIMITACIÓN DEL YACIMIENTO}

La necrópolis, de una superficie conocida de unos $700 \mathrm{~m}^{2}$, presentaba los enterramientos en una cota que se disponía siguiendo la antigua pendiente natural del terreno en dirección este, mirando al río Ter. El yacimiento (Fig. 2) se pudo delimitar bien por los lados norte, este y oeste, mientras que por el sur continúa por debajo de la avenida Jacint Verdaguer. No hay indicios de que la necrópolis termine aquí, sino al contrario, ya que incluso algunos de los enterramientos (núm. 60, 53 y 73) llegaban a adentrarse en el perfil meridional de la excavación. También hay un pequeño sector sin documentar, situado al noreste de la parte conocida del yacimiento.

Las cuatro campañas de excavación efectuadas permitieron localizar un total de 79 tumbas, distribui-

\footnotetext{
${ }^{4}$ Nolla y Sagrera 1993: 146.
}

das, como ya hemos apuntado antes, en dos sectores claramente diferenciados: 21 enterramientos, concentrados al noroeste de la zona excavada, eran de época romana (siglos II-v), y los 58 restantes eran de época visigoda y se pudieron datar en el siglo vI.

\section{LA NECRÓPOLIS ROMANA}

No entraremos en detalle por lo que respecta a la necrópolis romana, ya que se aleja del objeto de este estudio. Aun así, debemos describirla someramente ya que su existencia fue uno de los factores que condicionaron, en el siglo vi, la instalación de la necrópolis visigoda.

La necrópolis romana pertenecía sin duda a la vecina villa del Pla de l'Horta y estaba centrada por una construcción cuadrangular de unos 5 metros de lado, muy arrasada, que identificamos como los restos de un monumento funerario. Alrededor y en su interior se distribuían 21 enterramientos, 16 de los cuales eran cajas de tegulae, dos eran tumbas de obra de piedra y mortero de cal, dos más eran fosas y, finalmente, había un osario. Cuatro de los enterramientos contenían ajuar, consistente en un recipiente de cerámica: en total, dos cuencos y dos jarritas de cerámica común oxidada ${ }^{5}$.

Conocemos plenamente esta necrópolis, que se articuló tomando como centro la construcción cuadrangular, con unas tumbas más significativas en su interior y las demás circundándola por el exterior, siguiendo la orientación de sus paredes. Los enterramientos se inscriben perfectamente dentro de las tipologías habituales de las necrópolis romanas entre los siglos II y v.

\section{LA NECRÓPOLIS DE ÉPOCA VISIGODA: LAS TUMBAS}

La necrópolis visigoda se extiende al este y al sur de la romana (Fig. 2), probablemente entonces todavía visible, y de ella pudimos documentar un total de 58 enterramientos, todos orientados este-oeste. 30 tumbas eran fosas excavadas directamente en el subsuelo (Fig. 3). De ellas, 24 eran fosas simples, cinco de las cuales tenían alguna piedra o algún fragmento de tegula clavado a su alrededor y dos (núm. 14 y 62) conservaban losas de tapadera. Los seis enterramientos restantes eran fosas con los dos extremos delimitados con tegulae clavadas (Fig. 4).

\footnotetext{
5 Llinàs, Montalbán, Frigola y Merino 2005; Frigola, Llinàs, Merino y Montalbán 2006.
} 


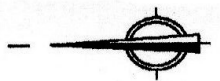

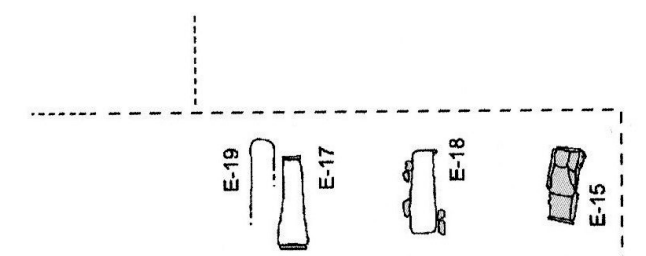
$\stackrel{⿱ 亠 凶}{\dot{u}}$

บ

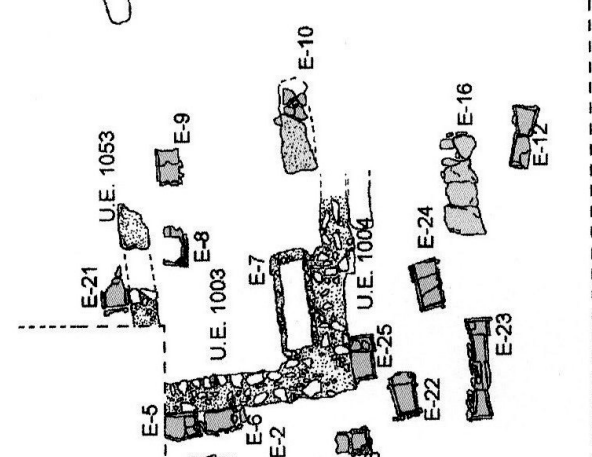

연
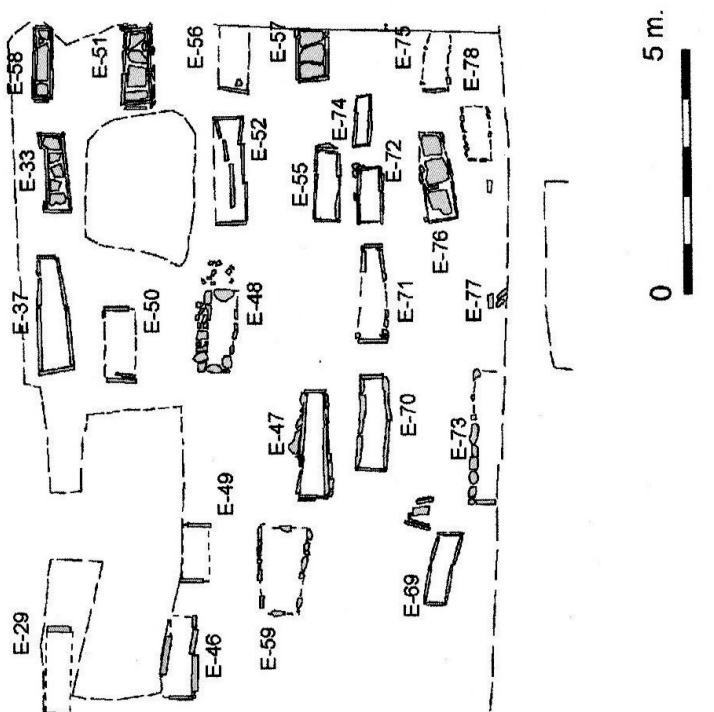

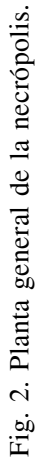

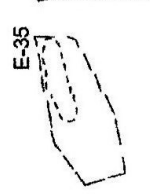

|

15

|

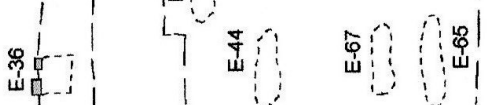

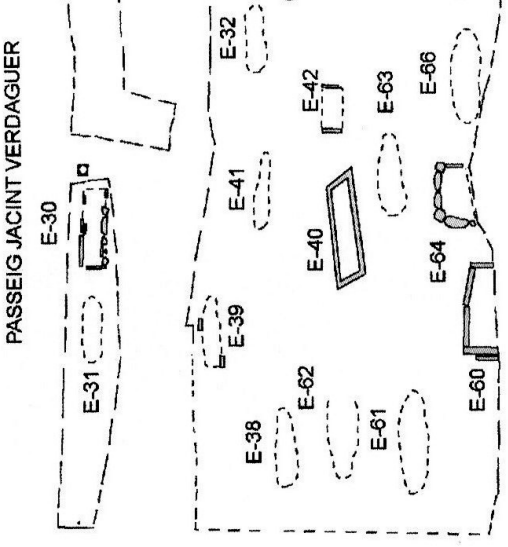



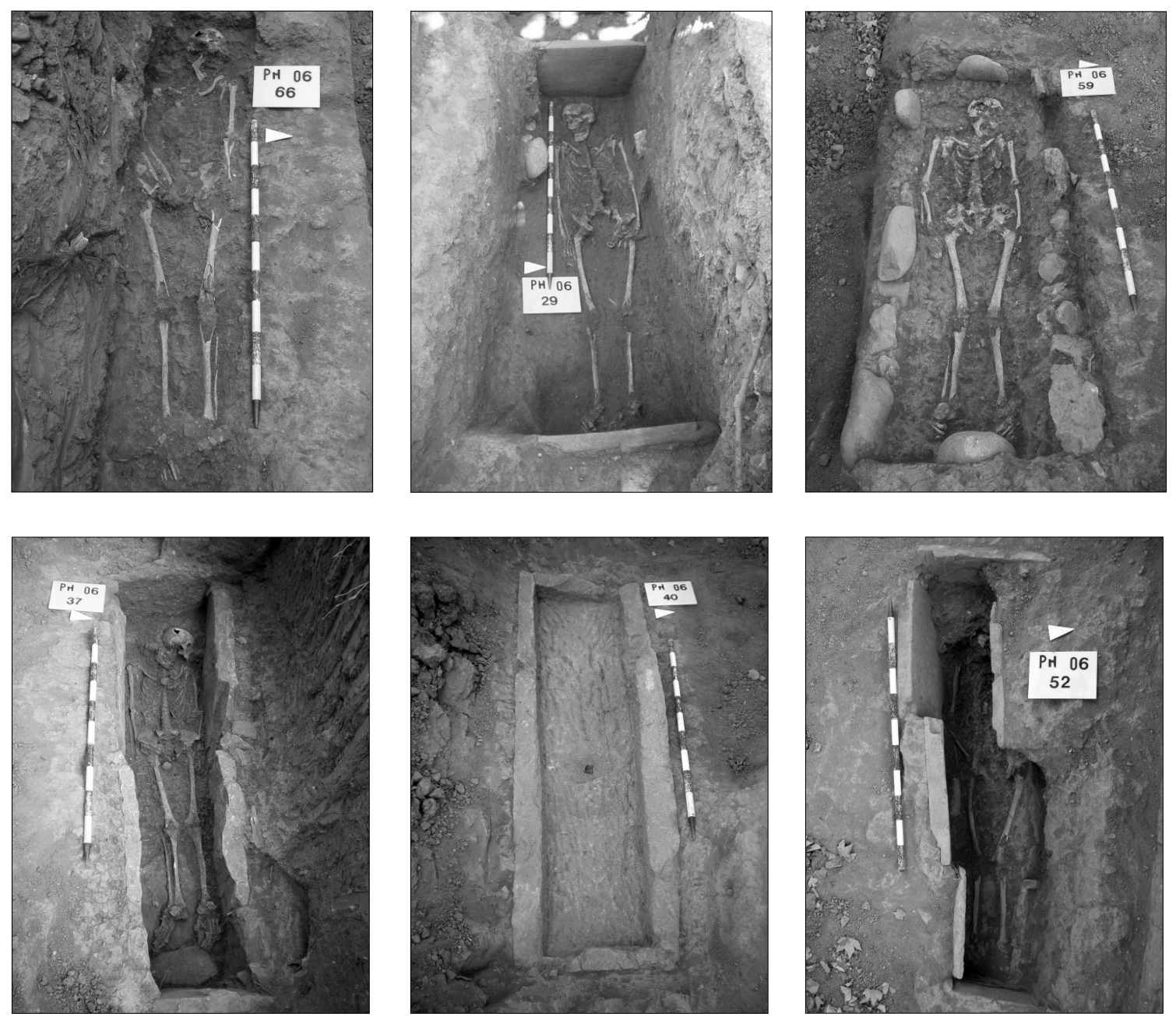

Figs. 3 a 8.-3. Fosa simple (E-66).-4. Fosa con los extremos delimitados con tegulae (E-29).-5. Fosa delimitada con piedras (E-59).-6. Cista (E-37).-7. Sarcófago (E-40).-8. Caja de tegulae (E-52).

Siete tumbas eran fosas delimitadas con piedras y fragmentos de tegula (Fig. 5) y solamente una de ellas (tumba 64) presentaba una cubierta de losas. Muy parecidas eran las tumbas núm. 48, 60 y 73, que presentaban, no obstante, mayor concentración de piedras y tegulae y se pueden considerar, de hecho, cajas mixtas.

Había 16 enterramientos en cajas de losas de piedra o cistas (Fig. 6), de los cuales 12 conservaban, total o parcialmente, la cubierta, hecha también de losas. 9 de estos sepulcros no tenían losas en el fondo. Finalmente, debemos mencionar un sarcófago liso de piedra (tumba 40; fig. 7) y una caja de tegulae (tumba 52; fig. 8).

El tipo de tumbas, con un claro predominio de las fosas y de las cistas o cajas de losas, es el habitual en cementerios de esta época ${ }^{6}$. Se puede observar cómo se ha abandonado prácticamente la inhumación en caja de tegulae, de la que tenemos un único ejemplar (tumba 52), sin embargo innegablemente visigodo, ya que proporcionó una hebilla de bronce con la aguja de base escutiforme.

Un dato interesante a comentar es la clara diferenciación del tipo de tumba según su ubicación dentro de la necrópolis. Así, vemos que casi todas las cajas de losas están concentradas en el sector sures-

${ }^{6}$ Los porcentajes se han situado generalmente entre el 35 $55 \%$ para las fosas y entre el $10-20 \%$ para las cistas (Cerrillo 1989: 98; Fuentes 1989: 247-249; Méndez y Rascón 1989: 109-114), con variaciones. Como en nuestro caso, estos dos tipos de tumba son los más frecuentes en necrópolis visigodas del siglo vi. 
te, mientras que mayoritariamente encontramos las fosas simples en los sectores suroeste y norte (Fig. 2). Se puede pensar en una diferenciación de tipo jerárquico (las cistas son enterramientos más costosos que las fosas), que podría incluso responder a agrupamientos familiares dentro del propio cementerio ${ }^{7}$. No podemos descartar, sin embargo, que esta distribución pueda ser debida a causas de tipo cronológico, según parece deducirse de los elementos de ornamentación personal recuperados, que nos indicarían que la necrópolis se fue extendiendo desde las proximidades del antiguo cementerio romano en dirección este. Más adelante trataremos los datos aportados en este sentido por los mencionados objetos de ornamentación.

\section{LOS RESTOS HUMANOS ${ }^{8}$}

Nueve de las 58 tumbas de la necrópolis visigoda aparecieron totalmente vacías (núm. 40, 42, 48, $60,73,75,77,78$ y 79) y en todas las restantes había un único ocupante; se recuperaron, pues, un total de 49 esqueletos. La mayor parte eran adultos, excepto 9 (núm. 13, 33, 39, 44, 49, 64, 69, 72 y 74) que eran infantiles de diversas edades. Si tenemos en cuenta los datos obtenidos a partir de las medidas de las tumbas, debemos añadir a la lista de infantiles las tumbas sin esqueleto núm. 42, 75, 77 y 79, por lo cual nos encontraríamos con un total de 45 tumbas destinadas a adultos y 13 a niños 9 .

El estudio antropológico realizado in situ en la excavación sobre 16 de estos individuos (núm. 37, $38,41,43,44,46,47,50,54,55,56,57,58,59,68$ y 74) permitió precisar la edad y el sexo de algunos de ellos, así como algunas patologías, como una articular degenerativa, con diversos casos de espondiloartrosis, propia de individuos maduros o seniles, una fractura consolidada en el antebrazo, problemas dentales e incluso una fractura antemortem de tibia y peroné que no llegó a consolidarse.

\footnotetext{
${ }^{7}$ Se han descrito, por ejemplo, agrupamientos familiares en necrópolis como las de Daganzo de Arriba y Camino de los Afligidos, ambas en Madrid (Ripoll 1989: 405-406).

${ }^{8}$ No podemos por ahora exponer un estudio antropológico detallado, que en estos momentos se halla en proceso de elaboración, por lo que nos limitamos a exponer tan sólo algunas generalidades.

9 Muy probablemente, la ausencia de restos humanos en estas tumbas se deba al fuerte componente agresivo de la tierra que los cubría. De hecho, en todas las tumbas infantiles de la necrópolis (e incluso en algunas pertenecientes a individuos adultos), el estado de conservación de los esqueletos era muy deficiente, conservándose sólo fragmentos de cráneo y de diáfisis de las extremidades.
}

La mayoría de los esqueletos estaban depositados en decúbito supino, excepto el individuo del enterramiento 58 que estaba colocado en una cista muy estrecha en posición decúbito lateral derecho ${ }^{10}$.

\section{LOS OBJETOS DE ORNAMENTACIÓN PERSONAL Y LOS AJUARES}

En 31 de las inhumaciones se hallaron objetos de ornamentación personal. En su mayoría, estos enterramientos proporcionaron una sola pieza, generalmente una hebilla, que iba acompañada de pequeños apliques en cuatro enterramientos, de una segunda hebilla en otras nueve tumbas y de botones en tres casos. Un enterramiento, el 63, proporcionó tres botones, sin ninguna hebilla.

Algunos enterramientos, además de objetos relacionados con la indumentaria del difunto, proporcionaron ajuares variados. Así, en el enterramiento 17 había tres cuentas de collar de pasta de vidrio (Fig. 9), en el 44 una ficha de juego de cerámica, en el 59 un cuchillo de hierro, en el 61 un objeto de hierro difícil de identificar, y en el 62 dos cuchillos, también de hierro (Fig. 10).

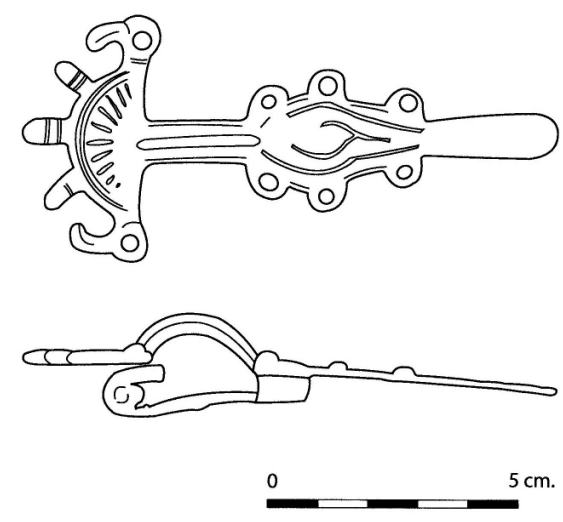

Fig. 9. Fíbula de arco de bronce. E-17.

Pero destacan, con diferencia y por su riqueza, los ajuares de los enterramientos 18, 32, 54 y 66. En el primer caso debemos mencionar un conjunto de pequeñísimas monedas bajoimperiales del tipo AE4 $4^{11}$

\footnotetext{
${ }^{10}$ Esta característica se suele relacionar con influencias islámicas, pero - aun con las debidas reservas-, no creemos que se trate de nuestro caso, ya que hasta ahora no hay ningún otro indicio que la necrópolis de Pla de l'Horta supere los inicios del siglo vII.

${ }^{11}$ El estudio numismático de estas monedas no se ha realizado todavía, puesto que se encuentran pendientes de limpieza y restauración.
} 


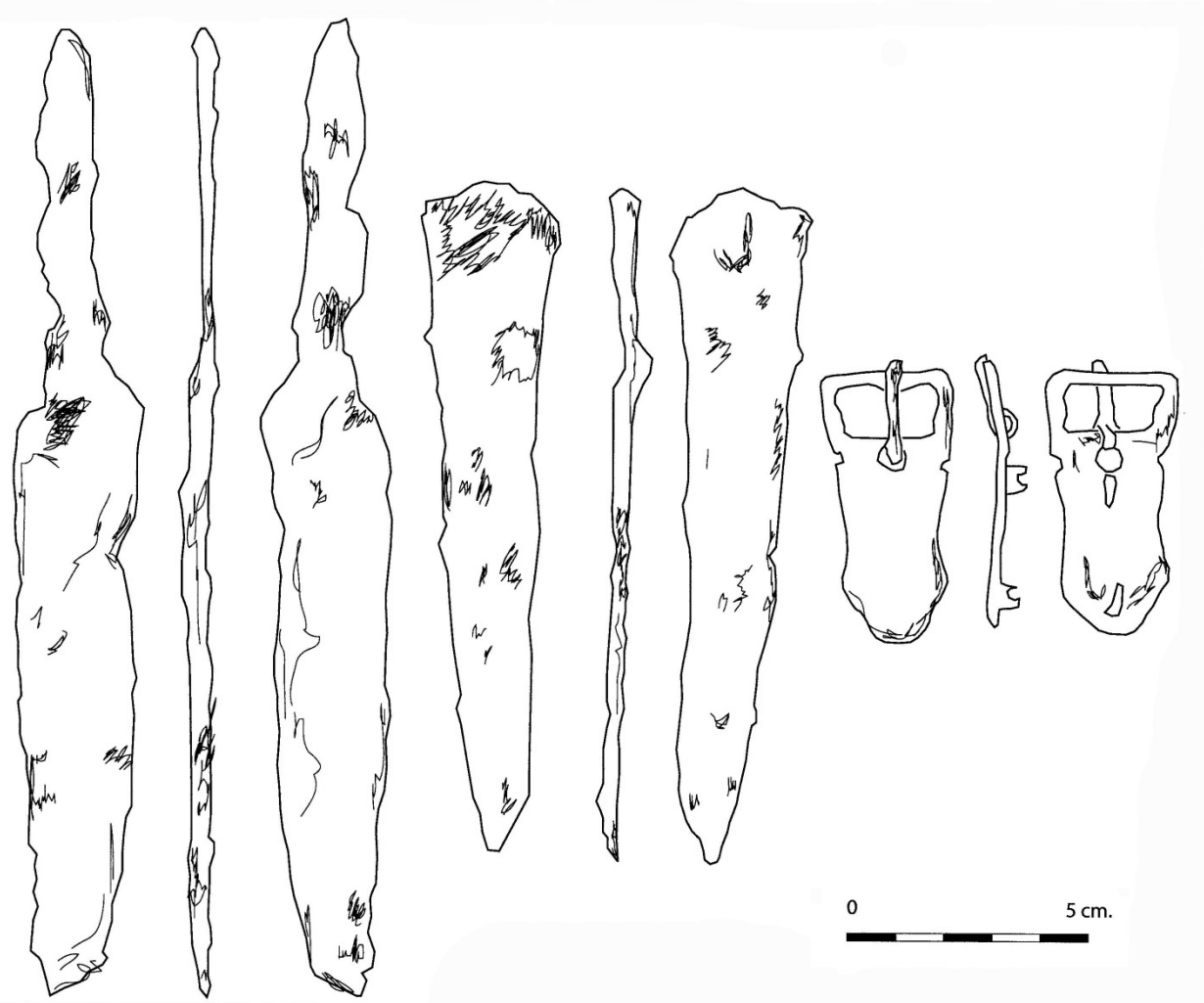

Fig. 10. Hebilla de bronce y cuchillos de hierro del E-62.

y dos cuchillos de hierro. En el enterramiento 32 (Figs. 11 y 12), al lado de una hebilla con su correspondiente aplique y de una segunda hebilla, aparecieron en el extremo distal del antebrazo derecho, juntos y dispuestos paralelamente a la extremidad, varios objetos de hierro (un cuchillo, un gancho y tres tallos con punta indeterminados), situados sobre una piedra plana alargada. En el enterramiento 54 se recuperaron un broche de cinturón con incrustaciones de pasta de vidrio (Fig. 13) y una gran fíbula muy elaborada, también con incrustaciones, ambos sobre la pelvis, en el lado izquierdo del cadáver. En esta inhumación se recuperaron también una hebilla de hierro, un punzón de bronce con una argolla, un pendiente anular también de bronce junto al temporal y unas cuentas de collar de pasta de vidrio en la zona del cuello. Finalmente, el individuo del enterramiento 66 portaba en el lado derecho de la caja torácica un cuchillo de grandes dimensiones dentro de una vaina, de la cual recuperamos el refuerzo de bronce de la punta. En esta inhumación también se hallaron dos hebillas, un anillo, una placa circular y un botón, todos de bronce, y otro cuchillo de hierro, más pequeño (Figs. 14 y 15).
La mayoría de objetos recuperados en la necrópolis son de bronce, material utilizado en hebillas, apliques, fíbulas, botones y anillos. Entre los objetos de este metal destacan por encima de todo las hebillas: se recuperaron 27, distribuidas en 21 enterramientos (en cuatro enterramientos —núm. 32, 47, 59 y 66- había dos y dos hebillas aparecieron fuera de contexto). Un buen número de estos objetos (12), de bronce fundido, tienen la aguja con una característica base escutiforme (fig. 16); la mayoría son ovaladas, pero hay dos rectangulares (enterramientos 47 y 66 ; figs. 14 y 17) ${ }^{12}$. Las hebillas con aguja de base escutiforme se utilizaron abundantemente a lo largo de los siglos v y vi en Hispania, especialmente en el centro ${ }^{13}$. A veces estas hebillas iban aso-

\footnotetext{
${ }^{12}$ Un paralelo catalán de la pieza del enterramiento 66 lo encontramos en la necrópolis de la calle Montmany 35 (Valldoreix, Barcelona) (Coll y Roig 2003: 832-833).

${ }^{13}$ Ripoll, 1985: 39. En Cataluña tenemos solamente cuatro paralelos conocidos de este tipo de hebillas: uno procede de la necrópolis del Hospital Militar de la Ciutadella de Roses (Girona), otro de la Pineda (Tarragona), otro de la villa romana de Els Antigons (Reus, Tarragona) y el cuarto de la necrópolis de la calle Sant Jaume, 121, de Granollers (Barcelona) (Nolla y Amich 1996-97: 1030-1031; VV.AA. 1999: 313-316; Coll y Roig 2003: 832-833).
} 


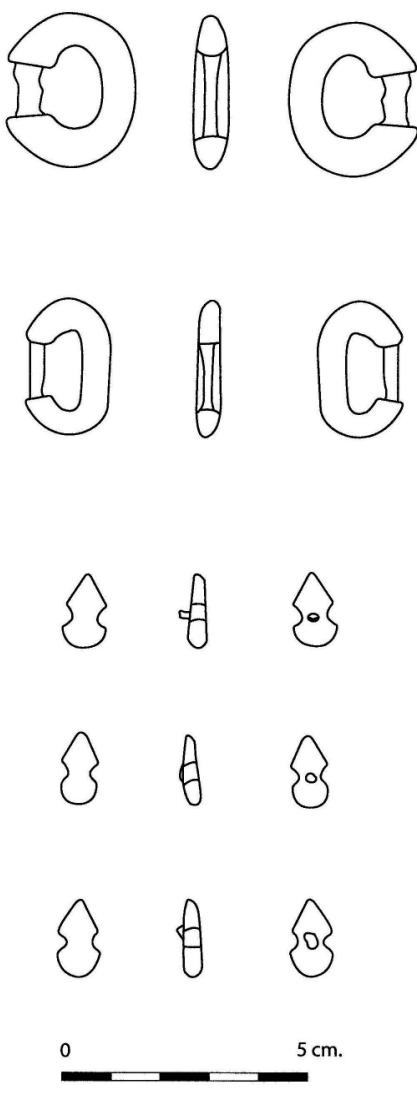

Fig. 11. Ajuar del E-32. Hebillas y apliques de bronce.

ciadas a unos pequeños apliques de bronce, también escutiformes, como ocurre en los enterramientos 18 , 29, 32 y 68 (Fig. 11). Aunque las hebillas podrían haber tenido centros de producción — por imitaciónen la península Ibérica, la única zona segura de producción de estos apliques es hoy por hoy Europa central ${ }^{14}$.

Cuatro hebillas tienen la aguja simple (enterramientos 53, 66, 71 y una sin contexto) y 4 más (enterramientos 38, 41, 64 y 76) la tienen de hierro, con la particularidad que la hebilla del enterramiento 76 tiene forma pentagonal (Fig. 18). De las hebillas de bronce de los enterramientos 32 (las dos), 44 y 59 no se recuperó la aguja.

Hay 3 hebillas de placa rígida (enterramientos 47, 62 y 72), la primera (Fig. 19) y la última (Fig. 20) con espina dorsal, cuerpo de lengüeta rectangular y cuatro lóbulos en los extremos, y la segunda - que es la única que ha conservado la aguja- sin decoración (Fig. 10). Este tipo de hebillas son propias de la segunda mitad avanzada del siglo vi y principios

\footnotetext{
${ }^{14}$ Ripoll 1985: 39.
}

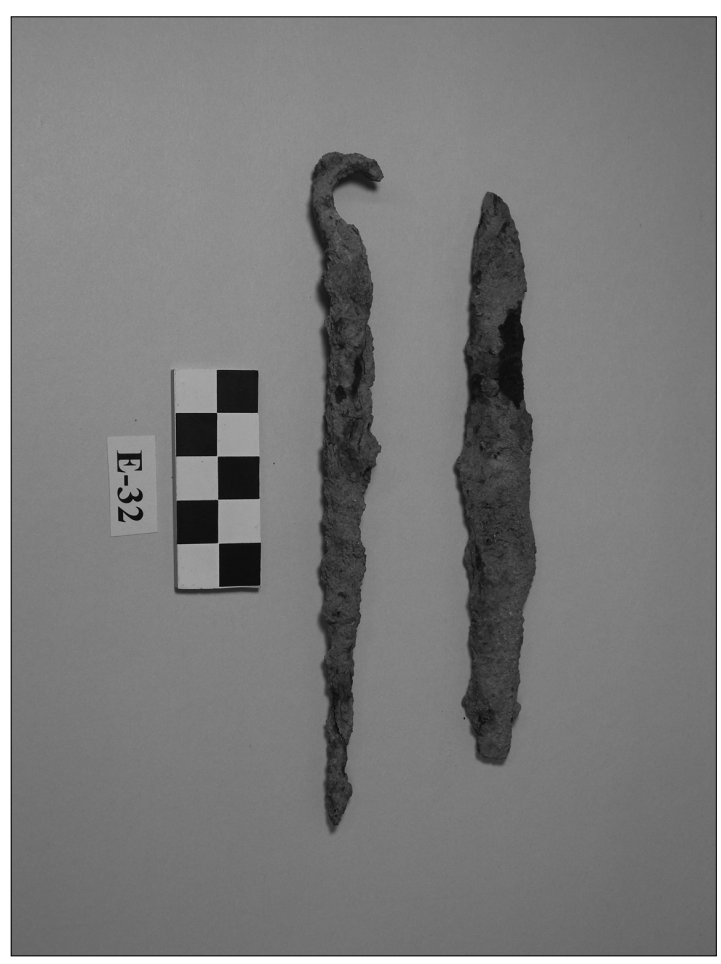

Fig. 12. Ajuar del E-32. Objetos de hierro.
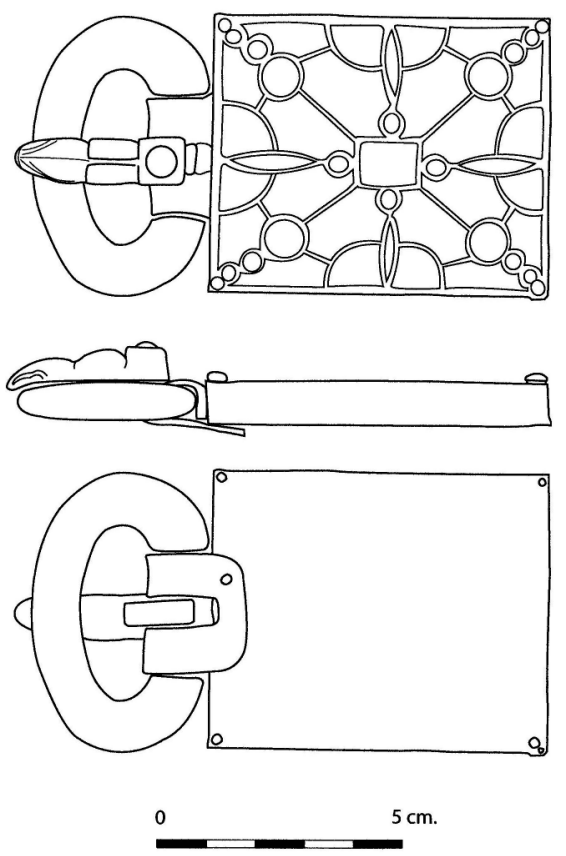

Fig. 13. Broche con incrustaciones de pasta de vidrio. E-54. 


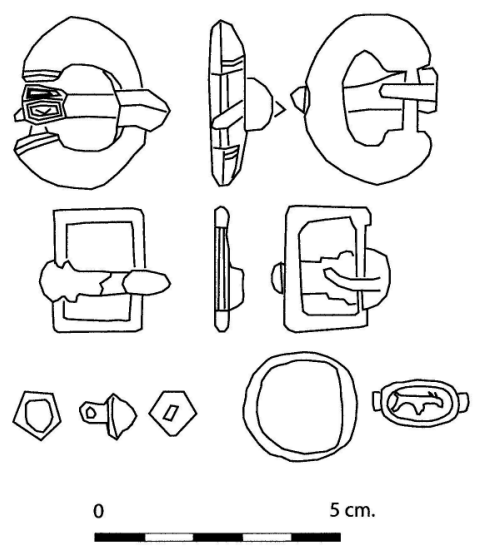

Fig. 14. Ajuar del E-66. Hebillas, anillo y botón de bronce.

del siglo VII ${ }^{15}$. Parece que el origen de estas piezas más tardías no sería tampoco visigodo, sino lombardo (muy especialmente los ejemplares con espina dorsal) y, desde Italia, se habrían extendido por otras zonas del Mediterráneo ${ }^{16}$, aunque muy probablemente también hubo talleres en el centro de la península Ibérica $^{17}$. En Cataluña conocemos un ejemplar procedente de la calle Montmany, 35, de Valldoreix, y otro de la necrópolis del Collet del Cargol (Sant Mateu de Bages), ambas en la provincia de Barcelona ${ }^{18}$.

Finalmente, debemos destacar el broche del enterramiento 54 (Fig. 13), con una placa rectangular decorada con un sistema de mosaico de celdillas con incrustaciones de pasta de vidrio que conforman un dibujo geométrico y simétrico, todo ello revestido por una fina capa de oro, parcialmente perdida. Se trata de un ejemplar del tipo I de esta clase de broches de cinturón y se puede datar entre finales del siglo v y la segunda mitad del siglo $\mathrm{VI}^{19}$. Este ejemplar es el primero de Cataluña que se ha hallado en una excavación arqueológica sistemática.

De las tres fíbulas recuperadas, la del enterramiento 44 es una fíbula de arco clásica. La del enterramiento 17 , en cambio, es una fíbula fundida en bronce, de arco del tipo III (Fig. 9); se compone en un extremo de una parte semicircular o placa de resorte, decorada con incisiones radiales, a cuyo alrededor hay cinco apéndices decorativos, los dos de los extremos en forma de cabeza de águila. El puente presenta dos profundas lineas incisas longitudinales

\footnotetext{
15 Ripoll 1998: 56-57 y 69-72.

${ }^{16}$ Ripoll 1998: 58-59 y 74-75.

${ }_{17}$ Ripoll 1998: 74

${ }^{18}$ Coll y Roig 2003: 832-833.

${ }^{19}$ Ripoll 1985: 47-49; Ripoll 1998: 47-54.
}

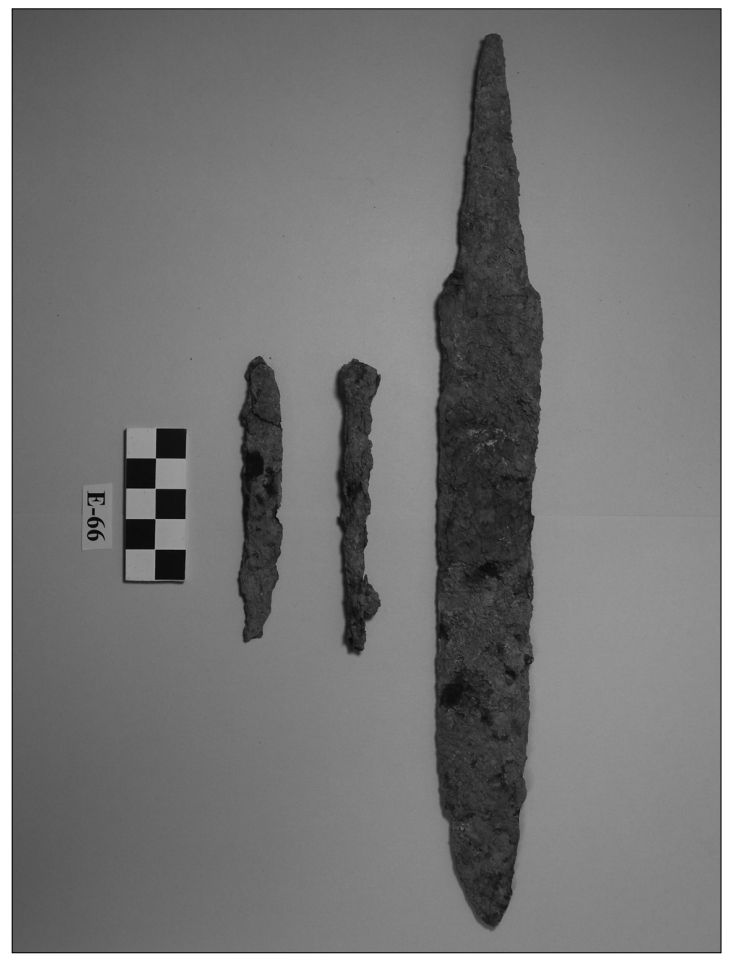

Fig. 15. Ajuar del E-66. Objetos de hierro.

y el enganche, de forma romboidal, está decorado también con lineas incisas y rematado externamente con seis apéndices engrosados de forma circular. El apéndice distal de la pieza es liso y en el reverso de la fíbula se conserva in situ la aguja de hierro. Este tipo de fíbulas, hechas a molde, pertenecen a la última fase de las fíbulas de arco visigodas y se datan en la segunda mitad del siglo vi. Parece que procedirían de un único taller, ubicado en el centro de la península Ibérica, y que serían propias de la vestimenta visigoda, que entró en desuso a partir de finales del siglo $\mathrm{vI}^{20}$. Este tipo de fíbula es raro en Cataluña, ya que solamente se conocen tres paralelos claros procedentes de Tarragona, pero de origen real dudoso ${ }^{21}$, a las cuales podríamos sumar otras cinco, halladas en Estagel ${ }^{22}$. De todas ellas, tan sólo una de las de Estagel pertenece, como la nuestra, al tipo III.

La tercera fíbula, hallada en el enterramiento 54, es un ejemplar muy mal conservado de fíbula de placas y arco en plata y bronce, de gran tamaño y de técnica trilaminar, compuesta por una placa de resorte semicircular, puente y placa de enganche de forma

\footnotetext{
${ }^{20}$ Ripoll 1985: 55-56.

${ }^{21}$ Palol 1950: 84-85 y fig.3; VV.AA. 1999: 306-307.

${ }^{22}$ Lantier 1943: 155.
} 

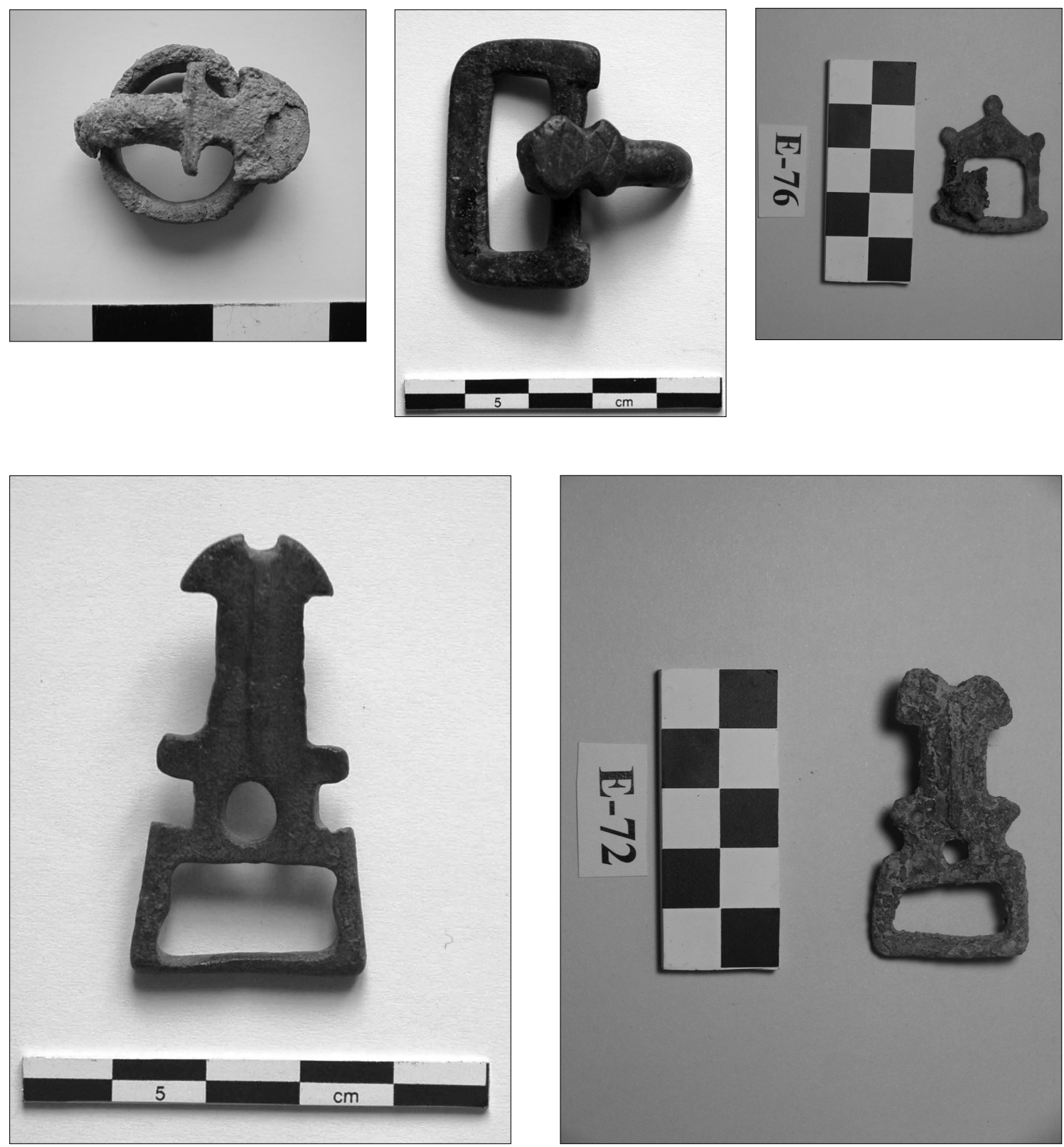

Figs. 16 a 20.-16. Hebilla de bronce con aguja de base escutiforme. E-19.-17. Hebilla de bronce rectangular. E-47.-18. Hebilla de bronce de forma pentagonal con aguja de hierro. E-76.-19. Hebilla de bronce de placa rígida. E-47.-20. Hebilla de bronce de placa rígida. E-72.

rectangular con ángulos redondeados. Las piezas que recubrían los extremos del puente estaban decoradas con mosaicos de pasta de vidrio, parecidos a los del broche hallado en el mismo enterramiento, y constituyen la parte mejor conservada y más destacable de esta pieza. Originaria de Europa Oriental, este tipo de fíbula es propio del siglo $\mathrm{v}$ y desaparece a prin- cipios del siglo $\mathrm{VI}^{23}$. Nuestro ejemplar es el primero que se ha encontrado en Cataluña.

Finalmente, entre las piezas de bronce de la necrópolis destacamos el anillo aparecido en el enterramiento 66, con decoración incisa en el sello, y los

\footnotetext{
${ }^{23}$ Ripoll 1985: 51-53 y 96-97.
} 
botones de los enterramientos 29 (uno), 50 (tres), 63 (dos) y 66 (uno), también frecuentes en las necrópolis visigodas (Fig. 14).

Referente al material de hierro, destacan también las hebillas, de las cuales se recuperaron 10 , todas de forma ovalada, pero debemos mencionar además las hojas de cuchillo (dos en los enterramientos 18 y 62 y una en los enterramientos 32, 59 y 66), así como varios punzones o herramientas indeterminadas, que aparecieron agrupadas en los enterramientos 32 y 66 (Figs. 10, 12 y 15).

En el enterramiento 18 se recuperaron una docena de pequeñas monedas, todas del tipo AE-4, acuñadas en la segunda mitad del siglo Iv. La mayoría aparecieron pegadas entre sí y en el momento de redactar este texto todavía se encuentran en proceso de restauración, por lo cual ha sido imposible hasta el momento realizar su estudio.

Entre el material de pasta de vidrio, finalmente, destacan las cuentas de collar de los enterramientos 17 y 54 .

\section{DATOS CRONOLÓGICOS}

Podemos situar perfectamente la necrópolis dentro del siglo vi. En primer lugar, debemos destacar que se diferencia claramente de la necrópolis romana precedente tanto por los tipos de sepulcro (entre los 58 enterramientos visigodos hay una sola tumba en caja de tegulae contra las 16 de 21 de la necrópolis romana) como por los ajuares y objetos recuperados.

La necrópolis tiene un momento de inicio que hemos de establecer a partir de algunos de los objetos recuperados en varias tumbas. Debemos fijarnos especialmente en el rico ajuar del enterramiento 54, donde destacan dos objetos únicos en nuestra necrópolis, que son el broche de cinturón de placa rectangular con incrustaciones de pasta de vidrio (Fig. 13) y la fíbula de placas y arco en plata y bronce. La hebilla tiene una cronología más laxa y se puede datar entre finales del siglo $\mathrm{v}$ y la segunda mitad del siglo $\mathrm{VI}^{24}$, pero la fíbula es de un tipo propio del siglo $\mathrm{v}$ o, como mucho, de principios del siglo $\mathrm{VI}^{25}$. Es muy probable, pues, que el material recuperado en este enterramiento nos esté dando un término post quem para el inicio de funcionamento de la necrópolis que deberíamos situar a finales del siglo $\mathrm{v}$ o a principios del siglo VI.

\footnotetext{
${ }^{24}$ Ripoll 1985: 47-49; Ripoll 1998: 47-54.

${ }^{25}$ Ripoll 1985: 51-53 y 96-97.
}

Respecto al momento final, viene marcado por dos factores. En primer lugar por los objetos de datación más moderna, que serían la fíbula de arco del tipo III del enterramiento 17 (fig. 9), de la segunda mitad del siglo $\mathrm{vI}^{26}$ y muy especialmente las tres hebillas de placa rígida (enterramientos 47, 62 y 72; figs. 10, 19 y 20), propias de la segunda mitad avanzada del siglo VI y principios del siglo $\mathrm{VII}^{27}$. En segundo lugar, debemos destacar la total ausencia de materiales propios del siglo vII, como las hebillas de placa rígida calada o las de placa rígida liriforme, de las cuales (a diferencia de todo lo hallado en Pla de l'Horta) sí tenemos ejemplares procedentes de otros lugares de la misma provincia de Girona, como Empúries ${ }^{28}$, Rose $^{29}$ o incluso un ejemplar procedente del vecino municipio de Sant Julià de Ramis ${ }^{30}$. Teniendo en cuenta estos dos factores, pues, podemos establecer con bastante fiabilidad un termino ante quem para el momento final de la necrópolis en torno a finales del siglo vI-principios del siglo vII, de lo que resulta, por lo tanto, un período de funcionamento máximo de unos cien años que abarcaría, a grandes rasgos, el siglo $\mathrm{vI}^{31}$.

No debemos olvidar en este punto un yacimiento cercano de gran importancia que puede tener mucha relación con nuestra necrópolis. Se trata de la necrópolis de Les Goges, compuesta por 207 fosas y situada a poco más de $2 \mathrm{~km}$ al noreste de Pla de l'Horta, en Sant Julià de Ramis. Esta necrópolis, donde entre otros objetos se hallaron dos monedas de Chindasvinto, fue fechada entre finales del siglo vIprincipios del VII y principios del $\mathrm{IX}^{32}$. Actualmente, después de los hallazgos del castellum de Sant Julià de Ramis (v. infra) y de la necrópolis visigoda de Pla de l'Horta, no podemos evitar relacionar con ellos la existencia de la necrópolis de Les Goges, que muy bien podría haber sucedido a Pla de l'Horta y haber

${ }^{26}$ Ripoll 1985: 55-56.

${ }^{27}$ Ripoll 1998: 56-57 y 69-72.

${ }^{28}$ Nolla y Sagrera 1995: 291-294.

${ }^{29}$ De Roses, contamos con un ejemplar hallado en la Ciutadella y cuatro más procedentes del poblado visigodo de Puig Rom, todos ellos propios del siglo VII (VV.AA. 1999: 322-323), a los cuales debemos añadir una sexta pieza, procedente de la Ciutadella, que se podría situar, esta sí, en el siglo VI (Palol 1950: 75).

${ }^{30}$ Palol 1950: 79-80.

${ }^{31}$ Exactamente igual que la mayoría de las grandes necrópolis visigodas «clásicas» de Castilla, como Castiltierra (Segovia), Herrera de Pisuerga (Palencia) o Madrona (Segovia), cuyo abandono se puede relacionar con las disposiciones unificadoras de Leovigildo y Recaredo. Aun así, algunas de estas necrópolis consiguen perdurar hasta el siglo vII, como Gózquez de Arriba (Madrid), Duratón o Carpio de Tajo (Toledo) $\mathrm{y}$, por lo tanto, cuestionarían esta tesis aceptada por muchos investigadores (Morín y Barroso 2005: 210).

32 Agustí et alii 1993. 
pertenecido a la misma comunidad que en ella se había enterrado durante el siglo vi. Otra hipótesis, ya formulada $^{33}$, defiende que el personal visigodo del castellum se habría enterrado a partir del siglo vII y después de su conversión al catolicismo alrededor de la iglesia de Sant Julià, situada en la cima misma de la montaña y muy cercana a la fortificación. En cualquier caso, la existencia de estos dos yacimientos ayudaría a explicar el abandono de nuestra necrópolis de Pla de l'Horta.

Finalmente, destacaremos un aspecto proporcionado por la tipología de las tumbas de Pla de l'Horta y su distribución espacial dentro del cementerio. Si observamos la planta general (Fig. 2), vemos claramente cómo la práctica totalidad de las cistas (14 de 16) se concentran en el sector sureste del área excavada, donde, en cambio, no encontramos ninguna de las 30 fosas simples, cuya distribución se reparte por todo el resto de la superficie de la necrópolis.

Si nos fijamos en los ajuares y objetos de ornamentación, las diferencias entre los dos tipos mayoritarios de sepulcros son también remarcables. Así, los enterramientos con ajuares más ricos (núms. 18, $32,54,62,66 \ldots)$ pertenecen exclusivamente a simples inhumaciones en fosa, mentras que los dieciséis induviduos inhumados en cistas proporcionaron en general materiales considerablemente más escasos.

Todo ello parece revelar una evolución espacial de la necrópolis que, a grandes rasgos y generalizando, se extendería a partir de los límites exteriores este y sur de la necrópolis romana preexistente, respetándola, en dirección hacia el este, donde encontraríamos la mayor parte de los enterramientos más modernos. Así, vemos que, a medida que avanza el siglo VI, los enterramientos con ajuares ricos dentro de unos sepulcros sencillos, son sustituídos por sepulcros en cista y con ajuares más pobres o inexistentes ${ }^{34}$.

En consecuencia, pues, y teniendo en cuenta que no todos los enterramientos de la parte «antigua» del cementerio de época visigoda son ricos y que no necesariamente la expansión de los enterramientos hacia el este tiene que ser un fenómeno absolutamente regular, podemos suponer con notables garantías que los enterramientos más antiguos se realizaron durante las primeras décadas del siglo vi mayoritariamente en tumbas de fosa y al sur de la necrópolis romana, y que, a partir de este primer sector, la necrópolis se

${ }^{33}$ VV.AA. 2006: 133.

${ }^{34}$ Este fenómeno ya fue constatado hace tiempo por G. Ripoll, quien apreció que en las necrópolis fechadas en el siglo VI el porcentaje de inhumados con sus objetos personales suele oscilar entre el 30 y el $40 \%$, mientras que en el siglo VII las cifras bajan hasta el $10 \%$ (Ripoll 1989: 417-418). fue extendiendo en dirección este hasta que, en las últimas décadas del siglo, paralelamente a una generalización de las tumbas en cista, alcanzaría los sectores más orientales del yacimiento.

\section{UNA COMUNIDAD VISIGODA EN LA TARRACONENSE ORIENTAL}

En primer lugar, debemos destacar que hasta ahora Pla de l'Horta es la única necrópolis del siglo vi con mayoría de enterramientos visigodos localizada en la Tarraconense oriental y, de hecho, en todo el levante de la península Ibérica, una zona donde todos los hallazgos cementeriales de esta época responden todavía generalmente a modelos tardorromanos ${ }^{35}$.

A modo de ejemplo, las hebillas, fíbulas y broches aparecidos en Pla de l'Horta son casi únicos hasta la fecha en toda la provincia de Girona, donde se conocen necrópolis tardoantiguas tan importantes como las de la Neápolis de Ampurias o de la Ciutadella de Roses, por citar dos ejemplos paradigmáticos ${ }^{36}$.

En el resto de Cataluña solamente podemos destacar los casos de cinco yacimientos que han proporcionado materiales afines: la calle Sant Jaume, 121 (Granollers, Barcelona), la calle Montmany, 35 (Valldoreix, Barcelona), Collet del Cargol (Sant Mateu de Bages, Barcelona), la Pineda (Tarragona) y la villa romana de Els Antigons (Reus, Tarragona) ${ }^{37}$. Sumados, los hallazgos de estos cinco yacimientos que se pueden considerar de tipo germánico y datar en el siglo vi se concretan en un total de sólo 19 tumbas y 12 objetos de ornamentación. Así pues, las características singulares de nuestra necrópolis la aproximan mucho más a los conjuntos similares de las gran-

${ }^{35}$ En el Pais Valenciano, por ejemplo, se han hallado en los últimos años algunas necrópolis fechadas en época visigoda, como la Almoina (Valencia), Beniopa (Gandía) y la Senda de l'Horteta (Alcàsser), pero las tipologías de los objetos de ornamentación personal, por mencionar un aspecto concreto y relevante (especialmente en Beniopa), difieren claramente de los habituales en las necrópolis visigodas del siglo VI.

${ }^{36}$ Destaca, sobre todo, la necrópolis ampuritana, compuesta por 449 tumbas fechadas entre finales del siglo III y la primera mitad del siglo VIII (Nolla y Sagrera 1995: 284-296). No se ha hallado en ella ni un solo objeto de ornamento personal ni ningún ajuar propios del siglo vi como los procedentes de Pla de 1'Horta o de otras necrópolis afines de la zona castellana. Por lo que respecta a la Ciutadella de Roses, hay un solo enterramiento, el núm. 5 de la necrópolis del área del Hospital Militar, con objectos de este tipo, concretamente dos hebillas, una con aguja de base escutiforme, y dos apliques, también escutiformes (Nolla y Amich 1996-97: 10301031 y 1039).

${ }^{37}$ Coll y Roig 2003; VV.AA. 1999: 306-307. 
des áreas del reino visigodo donde se concentran la mayoría de yacimientos de este tipo — la Meseta castellana- que no a los hallazgos dispersos y claramente minoritarios de la Tarraconense oriental.

La presencia de esta necrópolis en una zona y en una época dominadas por los enterramientos de tipo tardorromano debe responder forzosamente a la existencia en algún lugar cercano de una comunidad de origen visigodo y de confesión arriana, diferenciada de la mayoría hispanorromana y católica entonces predominante.

El contexto histórico parece claro. A partir de la desaparición en 472 de la administración romana en la Tarraconense oriental se produjo un momentáneo vacío de poder en la zona que fue cubierto con bastante celeridad por el nuevo estado visigodo. Establecido su dominio, la actuación goda en la actual Cataluña se limitó básicamente al control de las ciudades y de las vías de comunicación y, por lo tanto, su aportación poblacional fue mínima. La escasez de hallazgos como los de Pla de l'Horta corroborarían este fenómeno.

En 507, la derrota visigoda ante los francos en Vouillé destrozó la parte gala del reino, aunque se pudo preservar la región de Septimania, en el sureste de la Galia, que se convirtió en una zona expuesta continuamente a los ataques francos. Se abrió así una etapa —durante los reinados de Gesaleico (507-511), Amalarico (511-531) y Teudis (531-548) — en que la Narbonense y la Tarraconense oriental fueron el centro neurálgico del reino. Barcelona, Narbona y de nuevo Barcelona se convirtieron, alternativamente, en capitales del reino, y el recorrido de la antigua Vía Augusta entre estas dos ciudades actuó de auténtico cordón umbilical del estado. A medio camino, la ciudad de Girona creció también en importancia: en 517 fue sede de un concilio episcopal en el que asistieron la mayor parte de los obispos tarraconenses, y en 531 albergó un concilium del reino en el que el rey Teudis depuso al praefectus Hispaniarum Esteban ${ }^{38}$.

Fue en este contexto histórico cuando la comarca donde se halla Pla de l'Horta cobró cierta importancia. Como ya hemos apuntado, se trata de una zona atravesada de norte a sur por un tramo de la Vía Augusta al que jalonan dos puntos estratégicos: al sur, a $2 \mathrm{~km}$, la ciudad de Gerunda, con unas defensas reforzadas en el Bajo Imperio y cuyo antiguo kardo maximus era la propia vía; al norte, a $3 \mathrm{~km}$, el desfiladero del Congost y el paso de Costa Roja, vigi-

${ }^{38}$ Un panorama completo y detallado de esta época en Girona y alrededores lo debemos a N.M.Amich (2006). lados y controlados desde la montaña de Sant Julià por una destacable fortificación —castellum - de origen bajoimperial. Y, a poco más de 500 metros al sureste de Pla de l'Horta, el Pont Major, por donde la Vía Augusta cruzaba el curso del Ter.

Ante este panorama, se abren diversas hipótesis que permiten explicar las causas de la existencia de las tumbas visigodas halladas por nosotros, aunque ninguna pueda proporcionar — cabe destacarlo — una explicación definitiva.

En primer lugar, debemos preguntarnos si una parte de la villa romana habría podido sobrevivir al incendio que parece que la destruyó en el siglo v, o bien si en sus proximidades $-\mathrm{o}$ sobre sus propias ruinas - se habría podido desarrollar un nuevo hábitat, compuesto básicamente por población de origen germánico. Sería necesario reexcavar y reestudiar bien los restos de la villa para poder asegurarlo. En cualquier caso, descartamos que nos hallamos ante unos enterramientos visigodos que se ubicaron cerca de una antigua villa simplemente para reaprovechar sus restos, como sí pasa en otros lugares, puesto que Pla de l'Horta no sólo respeta las estructuras de la villa, sino incluso los de una de sus necrópolis. La ubicación de algunas necrópolis visigodas - como Tinto Juan de la Cruz, Camino de los Afligidos (Madrid), Cordiente (Guadalajara), Cacera de las Ranas (Aranjuez), Herrera de Pisuerga (Palencia) o Carpio de Tajo (Toledo) - cerca o reaprovechando restos de antiguas villas romanas cercanas a importantes vías de comunicación es un fenómeno que ha sido puesto en relación con una supuesta destrucción o desocupación del yacimiento romano ante la llegada y el asentamiento de $\operatorname{los}$ godos ${ }^{39}$. Aunque estos casos muestren evidentes paralelismos con nuestro Pla de l'Horta, es evidente que sin conocer con exactitud la estratigrafía arqueológica de la villa en este período, dificilmente podremos relacionarla con hechos históricos de esta índole.

En segundo lugar, debemos tener en cuenta la proximidad de la ciudad de Gerunda y su importancia política y estratégica en el siglo vi. No cabe duda de que la urbe debió albergar algunos elementos de población goda (autoridades públicas bajo el mando del comes civitatis, un cierto contingente militar...), quizá más importante que la que hubo en otras ciudades no tan bien situadas.

Pero es precisamente entorno a la interesantísima construcción militar de la montaña de Sant Julià donde recientemente se han buscado otras explica-

\footnotetext{
${ }^{39}$ Este aspecto es tratado, por ejemplo, por J. Morín y R. Barroso (2005: 206-208).
} 
ciones a la existencia de nuestras tumbas visigodas. Esta fortificación, o castellum, que cerraba y vigilaba un punto estratégico de la Vía Augusta, fue objeto de una importante refortificación coincidiendo, aproximadamente, con la consolidación del reino visigodo, entre finales del siglo $\mathrm{v}$ y principios del $\mathrm{vI}^{40}$. Esta reforma del castellum habría sido obra del estado visigodo, en estos momentos compuesto básicamente por elementos de procedencia germánica y confesión arriana, y habría ido acompañada de la dotación de un territorio, un fundus, que sería, precisamente, el de la antigua villa de Pla de 1'Horta ${ }^{41}$. Esta adscripción de un territorio al castellum tendría la función de proporcionar a sus habitantes las rentas y las materias primas suficientes (alimentarias sobre todo) para asegurar su pervivencia y su funcionamiento cotidiano. Teniendo en cuenta, pues, la reciente y evidente existencia de un cementerio anterior en este lugar, no sería raro que la guarnición y el personal godo del castellum y sus familiares decidiesen reutilizarlo.

En cualquier caso, es evidente que la proximidad de Gerunda, la posible pervivencia o reocupación de una antigua villa suburbana, el paso de la Vía Augusta y la existencia del castellum constituyen cuatro elementos que ayudarían a comprender la existencia de una comunidad goda en esta zona durante el siglo vi. Estos cuatro elementos ni mucho menos son excluyentes entre sí; al contrario, entendemos que su combinación fue seguramente determinante en el momento de la llegada y establecimiento de un contingente humano visigodo en esta zona. Esta comunidad, ya residiera en Gerunda, en el castellum, en Pla de l'Horta o incluso en los tres lugares a la vez, instaló su cementerio propio, arriano, al lado de la antigua necrópolis de la villa romana, cerca de la Vía Augusta y adecuadamente a medio camino entre la ciudad y el castellum. La estrecha cronología de la necrópolis (exclusivamente siglo vI), la cantidad de inhumados (cerca de 60, con la seguridad de que todavía quedan enterramientos por descubrir y que otros fueron destruídos hace tiempo) y el hecho que hayamos hallado en ella tanto mujeres, como hombres y niños son elementos que revelan que, como ya hemos remarcado anteriormente, muy probablemente nos encontremos ante una comunidad goda de cierta importancia, que sería la primera del siglo vi documentada arqueológicamente en la Tarraconense oriental y en todo el este de la antigua Hispania.

\footnotetext{
${ }^{40}$ VV.AA. 2006: 97-98 y 184-185.

${ }^{41}$ VV.AA. 2006: 185.
}

\section{A MODO DE CONCLUSIÓN}

Concluyendo, en Pla de l'Horta nos hallamos ante una necrópolis en buena parte comparable a la mayoría de las que se extienden en el centro de la península Ibérica y que responde a los parámetros más comunes de este tipo de necrópolis. Situada cerca de una gran vía de comunicación (la Vía Augusta) y de un río importante (el Ter), al lado de una antigua villa romana, se extiende por un terreno llano, suavemente inclinado hacia el este, en dirección a la vía y al río. Conocida de una manera parcial, está compuesta por un mínimo de 58 enterramientos, ninguno de ellos reaprovechado, la mayoría en fosa y unos cuantos (16) en cista, siendo absolutamente minoritarios otros tipos de tumba (una caja de tegulae y un sarcófago). En una parte importante de las inhumaciones se recuperaron objetos de ornamentación personal tipicamente germánicos (broches, hebillas, fíbulas...), y su cronología se pudo establecer con bastante precisión entre finales del siglo v y principios del VII como fechas extremas.

No dudamos de que nos hallamos ante un cementerio singular en esta zona, usado por elementos de procedencia goda y confesión arriana, estableciéndose así en este caso una relación directa entre el tipo de necrópolis y las características étnicoculturales de los inhumados en ella, un extremo que alguna vez se ha puesto en duda o se ha relativizado en otros casos similares $^{42}$. Desconocemos con certeza absoluta el hábitat de los enterrados en Pla de l'Horta, pero la presencia visigoda en esta comarca está sobradamente justificada dada la proximidad de la estratégica ciudad de Gerunda, la existencia de un castellum militar de control de una importante vía de comunicación e, incluso, la posibilidad de reocupación de una importante villa romana como fue Pla de l'Horta.

Finalmente, no se nos puede escapar que el abandono de la necrópolis coincide a grandes rasgos con las disposiciones unificadoras de Leovigildo y Recaredo y la conversión al catolicismo de la comunidad goda. Sin duda, los visigodos de la comarca (exceptuando probablemente los que residían en la misma ciudad de Gerunda, que ya tenía sus propias áreas cementeriales) fueron enterrados a partir de entonces en otra parte, quizás en la antigua iglesia de Sant Julià, pero también, por qué no, en un cementerio común con los hispanorromanos de la zona, que podríamos ubicar con toda probabilidad en la vecina y cercana necrópolis de Les Goges, fechada claramente a partir del siglo vII.

${ }^{42}$ Sin ir más lejos, la cercana necrópolis de Estagel, en la Cataluña francesa. 


\begin{tabular}{|c|c|c|}
\hline Enterramiento & Tipo de tumba & Ajuar \\
\hline E-13 & Fosa delimitada con piedras y tegulae & Hierro: 1 hebilla. \\
\hline $\mathrm{E}-14$ & Fosa simple & \\
\hline E-15 & Cista & \\
\hline $\mathrm{E}-17$ & Fosa con tegulae en los extremos & Bronce: 1 fibula. Hierro: un fragmento de anillo. Pasta de vidrio: 3 cuentas de collar. \\
\hline $\mathrm{E}-18$ & Fosa simple & Bronce: 1 hebilla y 2 apliques. Hierro: 2 hojas de cuchillo. Numismática: varias monedas AE-4 \\
\hline E-19 & Fosa simple & Bronce: 1 hebilla \\
\hline $\mathrm{E}-20$ & Fosa simple & \\
\hline $\mathrm{E}-28$ & Cista & \\
\hline $\mathrm{E}-29$ & Fosa con tegulae en los extremos & Bronce: 1 hebilla, 2 apliques y 1 botón. Hierro: 1 hebilla. \\
\hline $\mathrm{E}-30$ & Fosa delimitada con piedras y tegulae & \\
\hline E-31 & Fosa simple & \\
\hline E-32 & Fosa simple & Bronce: 2 hebillas y 1 aplique. Hierro: 1 cuchillo, 1 gancho y 3 tallos con punta, indeterminados. \\
\hline $\mathrm{E}-33$ & Cista & Hierro: 1 hebilla. \\
\hline $\mathrm{E}-34$ & Fosa simple & \\
\hline E-35 & Fosa simple & Hierro: Varios indeterminados \\
\hline $\mathrm{E}-37$ & Cista & Bronce: 1 hebilla. \\
\hline $\mathrm{E}-38$ & Fosa simple & Bronce: 1 hebilla. \\
\hline $\mathrm{E}-39$ & Fosa simple & \\
\hline $\mathrm{E}-40$ & Sarcófago & \\
\hline E-41 & Fosa simple & Bronce: 1 hebilla. \\
\hline E-42 & Fosa simple & \\
\hline$E-43$ & Fosa simple & \\
\hline E-44 & Fosa simple & Bronce: 1 fibula. Hierro: 1 hebilla. Cerámica: 1 ficha. \\
\hline E-45 & Fosa simple & Hierro: 1 hebilla y 1 pieza indeterminada. \\
\hline E-46 & Cista & \\
\hline E-47 & Cista & Bronce: 2 hebillas. \\
\hline E-48 & Caja mixta & \\
\hline E-49 & Fosa con tegulae en los extremos & \\
\hline $\mathrm{E}-50$ & Fosa con tegulae en los extremos & Bronce: 1 hebilla y 2 botones. \\
\hline E-51 & Cista & Hierro: 1 hebilla. \\
\hline $\mathrm{E}-52$ & Caja de tegulae & Bronce: 1 hebilla. \\
\hline E-53 & Fosa simple & Bronce: 1 hebilla. Hierro: 1 hebilla. \\
\hline E-54 & Fosa simple & Bronce: 1 hebilla, 1 fibula, 1 anilla y 1 punzón. Hierro: 1 hebilla. Pasta de vidrio: varias cuentas de collar \\
\hline E-55 & Cista & Hierro: 1 hebilla. \\
\hline E-56 & Fosa con tegulae en los extremos & Bronce: 1 hebilla. \\
\hline E-57 & Cista & \\
\hline E-58 & Cista & \\
\hline E-59 & Fosa delimitada con piedras y tegulae & Bronce: 2 hebillas y 1 pieza cuadrangular. Hierro: 1 placa \\
\hline $\mathrm{E}-60$ & Caja mixta & \\
\hline E-61 & Fosa simple & Bronce: 1 hebilla. Hierro: 1 objeto indeterminado. \\
\hline E-62 & Fosa simple & Bronce: 1 hebilla. Hierro: 2 hojas de cuchillo. \\
\hline E-63 & Fosa simple & Bronce: 2 botones. \\
\hline E-64 & Fosa delimitada con piedras y tegulae & Bronce: 1 hebilla. \\
\hline E-65 & Fosa simple & \\
\hline E-66 & Fosa simple & Bronce: 2 hebillas, 1 anillo, 1 placa y 1 refuerzo de vaina. Hierro: 2 hojas de cuchillo y varios indeterminados \\
\hline $\mathrm{E}-67$ & Fosa simple & \\
\hline E-68 & Fosa simple & Bronce: 1 hebilla, 1 aplique. \\
\hline E-69 & Cista & \\
\hline E-70 & Cista & \\
\hline E-71 & Cista & Hierro: 1 hebilla. \\
\hline E-72 & Cista & Bronce: 1 hebilla. \\
\hline E-73 & Caja mixta & \\
\hline E-74 & Cista & \\
\hline E-75 & Fosa delimitada con piedras y tegulae & \\
\hline E-76 & Cista & Bronce: 1 hebilla. \\
\hline E-77 & Fosa delimitada con piedras y tegulae & \\
\hline E-78 & Fosa delimitada con piedras y tegulae & \\
\hline E-79 & Fosa con tegulae en los extremos & \\
\hline
\end{tabular}




\section{BIBLIOGRAFÍA}

Agustí, B.; Casellas, L.E.; Foguet, G.; Llinàs, J.; LóPez, J.; Merino, J.; Pou, J. y Tió, X. (1993): «La necròpoli de les Goges (Sant Julià de Ramis, Gironès)», Tribuna d'Arqueologia 1991-1992, Generalitat de Catalunya, Barcelona: 117-128.

Амich, N.M. (2006): Les terres del nord-est de Catalunya a les fonts escrites d'època tardoantiga, Institut d'Estudis Gironins, Girona.

Brugada, J., coord. (2006): Sarrià de Ter, el paper de la història, CCG edicions, Girona.

Cerrillo, E. (1989): «El mundo funerario y religioso de época visigoda», III CAME, Oviedo: 91-101.

Coll, J.M. y RoIG, J. (2003): «Les sivelles de cinturó d'època visigoda (s. VI-VII) a les comarques de Barcelona», II Congrés d'Arqueologia Medieval i Moderna a Catalunya, Sant Cugat del Vallès: 831-836.

Frigola, J.; Llinàs, J.; Merino, J. y Montalbán, C. (2005): «Excavacions al Pla de l'Horta: la necrópolis de la vil·la romana», Parlem de Sarrià 51: 39-41.

- (2006): «La necrópolis romana i visigoda del Pla de 1'Horta (Sarrià de Ter, Gironès)», Vuitenes Jornades d'Arqueologia de les Comarques de Girona, Roses: 301-306.

FuENTES, A. (1989): La necrópolis tardorromana de Albalate de las Nogueras (Cuenca) y el problema de las denominadas Necrópolis del Duero, Cuenca.

LANTIER, R. (1943): Le cimetière wisigothique d'Estagel (Hautes-Pyrénées), Gallia 1: 153-188.

Linàs, J.; Montalbán, C.; Frigola, J. y Merino, J. (2005): «La necròpoli del Pla de l'Horta (Sarrià de Ter, Gironès)», en Nolla, J. M.; CASAS, J. y SANTAMARÍA, P., In suo fundo.La necròpoli oriental de la vil.la romana del Collet de Sant Antoni (Calonge, Baix Empordà) i els cementiris rurals de les antigues ciutitates d'Emporiae, Gerunda i Aquae Calidae, Estudi General, 25, Universidad de Girona, Diputación de Girona: 195-210.

Méndez, A. y Rascón, S. (1989): Los visigodos en Alcalá de Henares, Cuadernos del Juncal, 1, Alcalá de Henares.

Morín, J. y Barroso, R. (2005): «El mundo funerario de época visigoda en la comunidad de Madrid», I Jornadas de Patrimonio Arqueológico en la Comunidad de Madrid, Madrid: 199-236.

Nolla, J. M. (1982-83): «Algunes notes entorn de la vil.la romana del Pla de l'Horta de Sarrià de Dalt», Annals de l'Institut d'Estudis Gironins XXVII: 111-124.
Nolla, J. M. у Амісн, N. M. (1996-1997): «El cementiri de l'àrea de l'Hospital Militar de la Ciutadella de Roses», Annals de l'Institut d'Estudis Gironins XXXVII: 1027-1040.

Nolla, J. M.; Casas, J.; Santamaría, P. y Oliart, C. (2005): «La necròpoli oriental de la vil·la romana del Collet de Sant Antoni», en Nolla, J. M.; CASAS, J. y SANTAMARÍA, P.: In suo fundo.La necròpoli oriental de la vil.la romana del Collet de Sant Antoni (Calonge, Baix Empordà) i els cementiris rurals de les antigues ciutitates d'Emporiae, Gerunda i Aquae Calidae, Estudi General, 25, Universidad de Girona, Diputación de Girona: 11-103.

Nolla, J. M. y Sagrera, J. (1993): «Els mosaics de la vil.la romana del Pla de l'Horta (Sarrià de Ter)», Cypsela X: 145-158.

- (1995): Civitatis Impuritanae coementeria. Les necròpolis tardanes de la Neàpolis, Estudi General, 15, Universidad de Girona, Girona.

Nolla, J.M. y Sureda, M. (2005): «Les Cavorques (Sant Julià del Llor, Bonmatí, la Selva)», en NollA, J. M.; CAsas, J. y SANTAmaría, P: In suo fundo.La necròpoli oriental de la vil la romana del Collet de Sant Antoni (Calonge, Baix Empordà) i els cementiris rurals de les antigues ciutitates d'Emporiae, Gerunda i Aquae Calidae, Estudi General, 25, Universidad de Girona, Diputación de Girona: 129140.

Oliva, M. (1970): «Descubrimiento de una villa romana con mosaicos en Sarriá de Dalt (Gerona)», Revista de Gerona 52, 67-71.

Palahí, L. (1998): «El seguiment d'obres del Pla de l'Horta (Sarrià de Ter, el Gironès)», Quartes Jornades d'Arqueologia de les Comarques de Girona, Figueres: 204-208.

PALAhí, L. y Vivó, D. (1994): «Anàlisi estructural de la vil.la del Pla de l'Horta», Annals de l'Institut d'Estudis Gironins XXXIII: 157-170.

Palol, P. de (1950): «Fíbulas y broches de cinturón de época visigoda en Cataluña», Archivo Español de Arqueología XXIII: 73-98.

Puig, A. M. y Agustí, B. (2005): «La necròpoli del turó de l'Escorxador (Roses, Alt Empordà)», en Nolla, J. M.; Casas, J. y Santamaría, P.: In suo fundo. La necròpoli oriental de la vil.la romana del Collet de Sant Antoni (Calonge, Baix Empordà) $i$ els cementiris rurals de les antigues ciutitates d'Emporiae, Gerunda i Aquae Calidae, Estudi General, 25, Universidad de Girona, Diputación de Girona: 153-162.

Ripoll, G. (1985): La necrópolis visigoda de el Carpio de Tajo (Toledo), Excavaciones Arqueológicas en España, 142, Ministerio de Cultura, Madrid. 
- (1989): Características generales del poblamiento y la arqueología funeraria visigoda de Hispania, Espacio, Tiempo y Forma 2: 389-418.

- (1998): Toréutica de la Bética (s. VI y VII d.C.), Reial Acadèmia de Bones Lletres, Barcelona.

- (2007): «Las necrópolis visigodas. Reflexiones en torno al problema de la identificación del asentamiento visigodo en Occidente según los materiales arqueológicos», Hispania Gothorum. San Ildefonso y el reino visigodo de Toledo, Museo de Santa Cruz, Toledo: 59-74.

VV.AA. (1999): Del romà al romànic. Enciclopèdia Catalana, Barcelona.
VV.AA. (2001): Excavacions arqueològiques a la muntanya de Sant Julià de Ramis, 1. El sector de l'antiga església parroquial. Ayuntamiento de Sant Julià de Ramis-Diputación de Girona-Universidad de Girona, Girona.

VV.AA. (2006): Excavacions arqueològiques a la muntanya de Sant Julià de Ramis, 2. El castellum. Ayuntamiento de Sant Julià de Ramis-Diputación de Girona-Universidad de Girona, Girona.

Recibido el 18-12-07. Aceptado el 11-03-08. 